\title{
Double Blind Placebo Controlled Trial to Evaluate of the Effectiveness of a Dietary Supplement Rich in Carotenoids as Adjunct to Topical Lightening Cream for the Treatment of Melasma: A Pilot Study
}

\author{
Wan Lin Teo ${ }^{1 *}$, Emily Gan ${ }^{1}$, Anjali Jinghan ${ }^{1}$, Sai Yee Chuah ${ }^{1}$ Khaiat Alain ${ }^{2}$, Chee-Leok Goh ${ }^{1}$ and Steven Thng ${ }^{1}$ \\ ${ }^{1}$ National Skin Centre, Singapore \\ ${ }^{2}$ Seers Consulting, Singapore
}

\begin{abstract}
Objectives: To evaluate the efficacy of an oral supplement containing carotenoids as an adjunct to a topical cosmetic lightening cream for the treatment of melasma.

Methods: 44 subjects with melasma were recruited into a double-blinded, randomized, placebo controlled trial over 84 days at the Singapore National Skin Centre, to receive either an oral dietary supplement containing carotenoids or a placebo. All were prescribed a commercially available cream. Patients were assessed at onset, day 54 and day 84 by the Modified Melasma area and Severity Index (mMASI), photographic documentation, melanin and erythema indexes using a Mexameter®.
\end{abstract}

Results: 44 patients completed the study. The median mMASI score fell significantly in both groups (both $p<0.001)$. There was a greater decrease seen in those who received the oral supplement group $(-2.1$ vs $-1.8, p<0.379)$. The erythema score showed significant improvements in both groups, with greater improvement in the group on the oral supplement, compared to placebo (median difference $=-30, p=0.018$, vs median difference $=-20, p=0.020$ ).

Conclusion: Oral supplements containing carotenoids are potential adjuncts in melasma treatment. 1.5 Limitations: Small sample size and short study duration limit the observations noted in this study. Further larger-scale studies are required.

Keywords: Carotenoids; Melisma; Dietary supplement

\section{Introduction}

Melasma is a prominent skin problem, especially amongst dark skin individuals, presenting with varying degrees of hyperpigmentation on sun-exposed areas of the skin [1]. And has a significant psychosocial impact [2,3]. Exposure to ultraviolet (UV) radiation is regarded to be the most important factor in the pathogenesis of melasma, although hormonal factors (pregnancy, oral contraceptives) and ethnicity have also been implicated [4].

Treatment is challenging and the topical treatment of melasma mainly aims at photoprotection as well as disrupting the enzymatic processes of pigment production within melanocytes [4]. First line therapy includes topicals like tyrosinase inhibitors such as hydroquinone, kojic acid, as well as other topicals such as retinoids, topical corticosteroids and azelates [5]. In recent years, lesser known agents such as Arbutin, deoxyarbutin, Licorice extract, Rucinol and Resveratrol have also been reported to be useful [6-8]. Chemical peels are often added as second line therapy whilst laser therapies are reserved for patients who are refractory to conventional therapies, as they could cause paradoxical worsening of melisma [9-13].

Recent studies have documented protective effects of carotenoid micronutrients and phytochemicals against UVR associated skin damage [14]. When ingested in a high concentration, carotenoids concentrate in the skin and work by scavenging reactive oxygen species produced during photo-oxidative processes induced by UVR damage [15].

To date, lycopene is considered to be the most efficient singlet oxygen quencher of all the carotenoids derived from tomatoes and tomato products $[16,17]$. Dietary lycopene intake is associated with reduced prostate cancer risk [18]. In 2010, Rizwan et al. concluded that tomato paste containing lycopene provides protection against acute and longer-term aspects of photodamage, which correlated well with objective measurements of UVR erythemal sensitivity [19]. High intake of lycopene is likely going to colour the skin.
Early carotenoids are also present in substantial qualities in some tomato products and are readily absorbed. Both human and animal studies have demonstrated preferential accumulation of these carotenoids in skin tissues as well as bioactivity [20]. These carotenoids also possess absorption spectra in both in the UVB and UVA range, and are able to block the formation of melanin besides possessing antiinflammatory, anti-oxidant properties and can cause reduction of the existing melanin in melanocytes [19,21].

Crystal Tomato $^{\circledR}$ is a dietary supplement containing high concentrations of early carotenoids derived from a specific, nongenetically-modified tomato. The objective of this study was to examine the efficacy of this oral supplement as compared to a placebo as an adjunct to a topical cosmetic lightening cream for the treatment of melasma.

\section{Materials and Methods}

\section{Subjects and study design}

This was a double-blind, randomized, placebo-controlled trial comparing Crystal Tomato $^{\circ}$, an oral supplement containing carotenoids, as an adjunct to a topical lightening cream in the treatment

*Corresponding author: Wan-Lin Teo, National Skin Centre, Mandalay Road Singapore 308205, Singapore, Tel: 037468 /6580; E-mail: wanlinteo@gmail.com

Received November 26, 2014; Accepted December 06, 2014; Published December 08, 2014

Citation: Teo WL, Gan E, Jinghan A, Chuah SY, Alain K, et al. (2015) Double Blind Placebo Controlled Trial to Evaluate of the Effectiveness of a Dietary Supplement Rich in Carotenoids as Adjunct to Topical Lightening Cream for the Treatment of Melasma: A Pilot Study. Pigmentary Disorders 2: 164. doi: 10.4172/2376-0427.1000164

Copyright: ( 2015 Teo WL, et al. This is an open-access article distributed under the terms of the Creative Commons Attribution License, which permits unrestricted use, distribution, and reproduction in any medium, provided the original author and source are credited. 
of melasma. The study was performed according to the Declaration of Helsinki. Local ethics approval was granted and written informed consent was obtained from the National Healthcare Group Ethics Board.

\section{Inclusion and exclusion criteria}

Patients with a diagnosis of melasma, aged between 25 to 60 years old, of skin type 3 and 4 were recruited into the trial. Exclusion criteria were: pregnant or lactating patients, patients assessed to be uncooperative, participants in other clinical studies, patients with known contact allergy to any of the ingredients in topical medication, as well as known allergies to food supplements containing tomato. Informed consent was taken from all recruited patients before proceeding with the trial. There is no effect on seasonality on the recruitment period as Singapore is a tropical country located on the equator and receives an equal amount of sunshine throughout the year.

\section{Initial assessment}

All recruited patients attend a baseline assessment, during which the following information was collected: demographic data, duration of disease, other associated skin conditions, past medical history, known drug allergies and contact allergies, number of hours spent outdoor per day, use of previous skin lightening agents/laser/light therapies, frequency of usage of sunscreen.

Physical examination was carried out by a dermatologist and overall severity was assessed and scored via the modified Melasma Area and Severity Index.

\section{Randomization and blinding procedures}

Randomization was carried out via a computer-generated randomization list, prepared by a statistician and sent to the independent pharmacist to be used for preparation and labelling of the study drugs. The randomization list was accessible only by the biostatistician and designated personnel directly responsible for packaging and labelling of study materials. Subjects were randomly assigned in a ratio of 1:1 to either active supplement or placebo.

The study pill and placebo were similarly packaged in identical containers and determined to be identical in appearance. The containers were labelled with the trial number and other details according to local requirements. Adequate supply of study pill was dispensed on day 0 and stored at room temperature. Using this method both the patient and the investigator were blinded to the pill dispensed. Unblinding of the study occurred only after all the patients had completed the study.

\section{Treatment regimen}

The trial product Crystal Tomato ${ }^{\circ}$ contains colourless carotenoidrich tomato powder $(800 \mathrm{mg} /$ caplet $)$ and L-Cysteine $(50 \mathrm{mg} / \mathrm{caplet})$. The margin of safety has been established and is $>5000$.

The pills were distributed by a pharmacist who was uninvolved in the study assessments and the subjects were instructed to take the oral pills, one tablet once in the morning. In addition, all subjects were prescribed a lightening cream containing several tyrosinase inhibitors (like Kojic palmitate, Niacinamide, Alpha-arbutin), antioxidants, as well as mild exfoliating acids as active ingredients. The subjects were also prescribed a physical sunblock for daytime use, educated on the need for sun protection and avoidance and also informed to stop all other topical products for their face, except their own cleansers. Specifically, the importance of applying sunblock half an hour prior to sun exposure as well as re-applying the sunblock every 2 hours was reinforced. Subjects were asked to continue with their usual diets during the study. All medications (prescription and over the counter), vitamin and mineral supplements, and / or herbs taken by the participant were documented.

\section{Clinical evaluation}

As far as possible, subjects were assessed by the same physician at baseline (visit 1) and followed up at Day 56 and Day 84. When this arrangement was not possible, the patient was assessed by another member of the pigment team in the National Skin Centre. At onset (visit 1), visit 2 (day 54) and at the conclusion of the study (day 84), they were assessed using the Modified Melasma Area and Severity Index (mMASI), photographic documentation, melanin and erythema index using a Mexameter ${ }^{\bullet}$ (Courage \& Khazaka).

\section{Primary efficacy variable}

The primary efficacy variable is the reduction in the modified Melasma Area and Severity Index scores between Visit 1 and Visit 3. At baseline and each review, the modified MASI score was calculated by subjective assessment of 2 factors: area (A) of involvement, and darkness (D) at the forehead (f), right malar region ( $\mathrm{rm})$, left malar region (lm), and chin (c). The scoring was based on visual inspection by a dermatologist. The modified MASI score is then calculated as below.

Modified MASI total score $=0.3 \mathrm{~A}(\mathrm{f}) \mathrm{D}(\mathrm{f})+0.3 \mathrm{~A}(\mathrm{~lm}) \mathrm{D}(\mathrm{lm})+$ $0.3 \mathrm{~A}(\mathrm{rm}) \mathrm{D}(\mathrm{rm})+0.1 \mathrm{~A}(\mathrm{c}) \mathrm{D}(\mathrm{c})$

The range of the total score is 0 to 24 . Area and darkness are scored as follows:

Area of involvement:

$0=$ absent, $1=<10 \%, 2=10 \%-29 \%, 3=30 \%-49 \%$,

$4=50 \%-69 \%, 5=70 \%-89 \%$, and $6=90 \%-100 \%$;

Darkness: $0=$ absent, $1=$ slight, $2=$ mild, $3=$ marked and $4=$ severe

\section{Secondary efficacy variable}

The secondary efficacy variable is the reduction in melanin and erythema index as measured by the Mexameter. ${ }^{\circ}$ A fixed area of skin deemed by the investigator to be the darkest on the patient was assessed on all the visits. The melanin and erythema index was measured at this area, and an average of 3 readings were taken.

In addition to the mMASI scores as well as the melanin and erythema index scores, standard photographs were also taken at baseline (day 0) and on at Visit 2 (Day56) and Visit 3 (Day 84) using the VISIA ${ }^{\oplus}$ Complexion Analysis System (Canfield Imaging Systems) with standardized camera settings and positioning.

Three angles were standardized for photographing the face of each patient before and after treatment: left $37^{\circ}$, center $0^{\circ}$, right $37^{\circ}$.

\section{Clinical assessments of safety and tolerability}

Patients were asked about the symptoms of burning, redness, pruritus and swelling at each review. Any adverse event-was recorded.

\section{Statistical analyses}

There have not been any previous scientific reports regarding the use of an oral food dietary supplement containing carotenoids on the treatment of melasma. Hence, no statistical rationale for sample size exists. 
Citation: Teo WL, Gan E, Jinghan A, Chuah SY, Alain K, et al. (2015) Double Blind Placebo Controlled Trial to Evaluate of the Effectiveness of a Dietary SupplementRichinCarotenoidsasAdjuncttoTopicalLighteningCreamfortheTreatmentofMelasma:APilotStudy.PigmentaryDisorders2:164.doi: 10.4172/2376-0427.1000164

Page 3 of 6

\begin{tabular}{|c|c|c|c|c|}
\hline & Total & Active & Placebo & \multirow{2}{*}{ p-value } \\
\hline & $(n=44)$ & $(n=22)$ & $(n=22)$ & \\
\hline Age, median (min-max) & $50.5(29.0-56.0)$ & $50.5(29.0-54.0)$ & $50.0(31.0-56.0)$ & 0.805 \\
\hline Age of onset, median (min-max) & $43.0(3.0-53.0)$ & $44.0(24.0-50.0)$ & $41.5(3.0-53.0)$ & 0.663 \\
\hline Duration (years), median (min-max) & $5.0(1.0-51.0)$ & $5.0(1.0-23.0)$ & $4.5(2.0-51.0)$ & 0.859 \\
\hline No. of Tablets used, median (min-max) & $87.0(46.0-90.0)$ & $90.0(46.0-90.0)$ & $87.0(53.0-90.0)$ & 0.867 \\
\hline Race, count (\%) & & & & 0.683 \\
\hline Chinese & $31(70.5)$ & $17(77.3)$ & $14(63.6)$ & \\
\hline Malay & $3(6.8)$ & $1(4.5)$ & $2(9.1)$ & \\
\hline Indian & $4(9.1)$ & $1(4.5)$ & $3(13.6)$ & \\
\hline Others & $6(13.6)$ & $3(13.6)$ & $3(13.6)$ & \\
\hline Gender, count (\%) & & & & 1.000 \\
\hline Male & $6(13.6)$ & $3(13.6)$ & $3(13.6)$ & \\
\hline Female & $38(86.4)$ & $19(86.4)$ & $19(86.4)$ & \\
\hline Hours spent outdoor, count (\%) & & & & 0.802 \\
\hline$<1 \mathrm{hr}$ & $12(27.3)$ & $7(31.8)$ & $5(22.7)$ & \\
\hline $1-2 \mathrm{hrs}$ & $19(43.2)$ & $9(40.9)$ & $10(45.5)$ & \\
\hline $3-4 \mathrm{hrs}$ & $9(20.5)$ & $5(22.7)$ & $4(18.2)$ & \\
\hline $5-7 \mathrm{hrs}$ & $4(9.1)$ & $1(4.5)$ & $3(13.6)$ & \\
\hline Previous skin lightening agents used, count (\%) & $40(90.9)$ & $20(90.9)$ & $20(90.9)$ & 1.000 \\
\hline Sunscreen used, count (\%) & & & & 1.000 \\
\hline Ocassionally if I remember & $1(2.3)$ & $0(0.0)$ & $1(4.5)$ & \\
\hline 1-2 times per week & $1(2.3)$ & $1(4.5)$ & $0(0.0)$ & \\
\hline Once a day & $32(72.7)$ & $16(72.7)$ & $16(72.7)$ & \\
\hline Twice a day & $7(15.9)$ & $3(13.6)$ & $4(18.2)$ & \\
\hline Previous laser / light therapy used, count (\%) & $14(31.8)$ & $5(22.7)$ & $9(40.9)$ & 0.195 \\
\hline
\end{tabular}

Table 1: Summary Statistics of Baseline Variables

\begin{tabular}{|c|c|c|c|c|c|c|c|}
\hline \multicolumn{2}{|c|}{ Table 1Treatment } & $\begin{array}{c}\text { Visit } 1 \text { (Day 0) Total } \\
\text { mMASI }\end{array}$ & $\begin{array}{l}\text { Visit } 2 \text { (Day 54) } \\
\text { Total mMASI }\end{array}$ & $\begin{array}{c}\text { Visit } 3 \text { (Day 84) } \\
\text { Total mMASI }\end{array}$ & $\begin{array}{c}\text { (Visit } 2 \text { - Visit 1) } \\
\text { Total mMASI }\end{array}$ & $\begin{array}{l}\text { (Visit } 3 \text { - Visit 1) } \\
\text { Total mMASI }\end{array}$ & $\begin{array}{c}\text { (Visit } 3 \text { - Visit 2) } \\
\text { Total mMASI }\end{array}$ \\
\hline \multirow[t]{7}{*}{ Active } & $\mathrm{N}$ & 17 & 17 & 17 & 17 & 17 & 17 \\
\hline & Mean & 5.1 & 3.3 & 2.7 & -1.8 & -2.4 & -0.6 \\
\hline & Std. Deviation & 1.6 & 1.5 & 1.2 & 1.2 & 1.4 & 1.3 \\
\hline & Minimum & 2.8 & 1.6 & 1 & -3.6 & -4.8 & -3.9 \\
\hline & Maximum & 7.5 & 6.7 & 5.5 & 0.3 & -0.1 & 1.2 \\
\hline & Median & 5.2 & 2.8 & 2.8 & -2.1 & -2.1 & -0.6 \\
\hline & \multicolumn{4}{|c|}{$p$-value for testing the change from previous visit } & 0.001 & $<0.001$ & 0.083 \\
\hline \multirow[t]{7}{*}{ Placebo } & $\mathrm{N}$ & 19 & 19 & 19 & 19 & 19 & 19 \\
\hline & Mean & 5.3 & 3.1 & 3 & -2.2 & -2.3 & -0.2 \\
\hline & Std. Deviation & 2.7 & 1.4 & 1.5 & 2.2 & 2.3 & 0.8 \\
\hline & Minimum & 2.2 & 1 & 1 & -8.4 & -8.4 & -1.8 \\
\hline & Maximum & 10.3 & 5.8 & 5.8 & 0 & 0 & 1.8 \\
\hline & Median & 4.3 & 2.8 & 2.8 & -1.5 & -1.8 & 0 \\
\hline & \multicolumn{4}{|c|}{$p$-value for testing the change from previous visit } & 0.001 & $<0.001$ & 0.365 \\
\hline \multicolumn{5}{|c|}{ p-value for testing the difference in change between Active and Placebo } & 0.876 & 0.379 & 0.244 \\
\hline
\end{tabular}

1) The median (min-max) mMASI score for the Active group for Visit 1 was 5.2 (2.8-7.5), Visit 2 was 2.8 (1.6-6.7) and Visit 3 was 2.8 (1.0-5.5).

2) The median (min-max) mMASI score for the Placebo group for Visit 1 was 4.3 (2.2-10.3), Visit 2 was 2.8 (1.0-5.8) and Visit 3 was 2.8 (1.0-5.8).

3) There was significant improvement in the mMASI score $(p<0.001$, median difference $=-2.1)$ from the Visit 1 to Visit 3 for Active group.

4) There was significant improvement in the mMASI score $(p<0.001$, median difference $=-1.8)$ from the Visit 1 to Visit 3 for Placebo group.

Table 2: Comparison of mMASI Score between Active and Placebo groups

The statistical analyses were performed using SPSS Version 22. All participants who received the study products were included in the intention-to-treat analysis. Summary statistics were reported for baseline variables. Chi-square test or Fisher's exact test was used to test the association of each categorical baseline variable with the treatment group.

Analysis of variables with a non-normal distribution, such as the improvement of Melasma for each treatment group (differences in the changes in mMASI and Mexameter scores from Visit 1) was carried out using the Wilcoxon signed-rank test for paired data. A p-value less than 0.05 was considered statistically significant.

\section{Results}

\section{Study population}

The demographics of the study population are as shown in Table 1. 44 patients aged $29-56$ years (mean \pm SD; $49 \pm 6.16$ ) with skin type III and IV were enrolled into the study. These comprised of 38 females and 
Citation: Teo WL, Gan E, Jinghan A, Chuah SY, Alain K, et al. (2015) Double Blind Placebo Controlled Trial to Evaluate of the Effectiveness of a Dietary SupplementRichinCarotenoidsasAdjuncttoTopicalLighteningCreamfortheTreatmentofMelasma:APilotStudy.PigmentaryDisorders2:164.doi: 10.4172/2376-0427.1000164
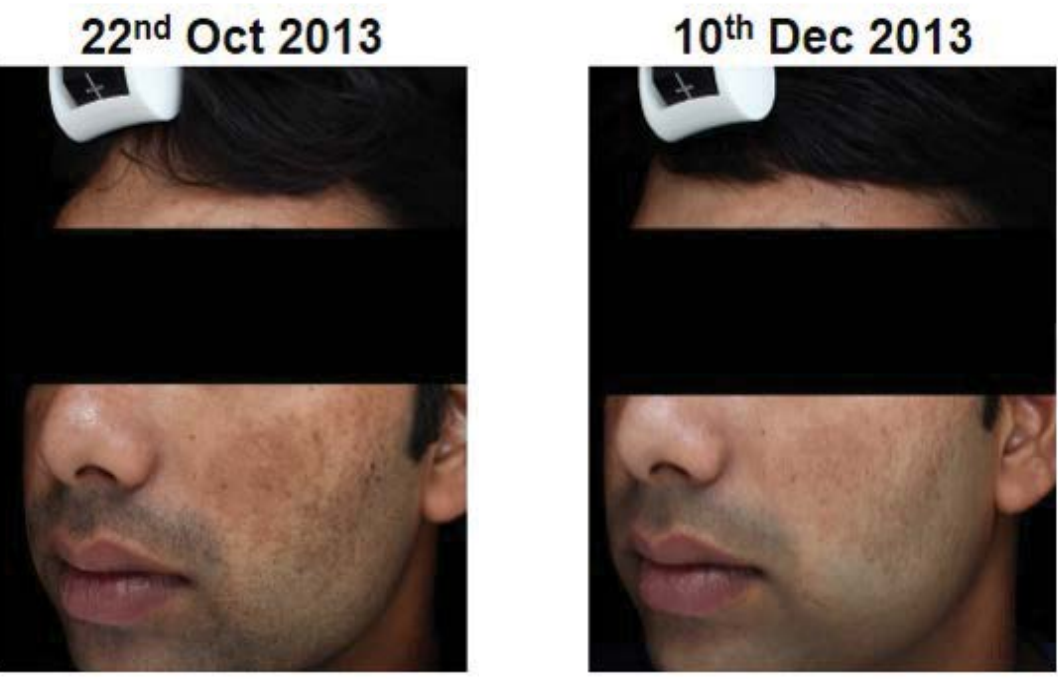

Figure 1: Skin pigmentation compared with baseline

\begin{tabular}{|c|c|c|c|c|c|c|c|}
\hline \multicolumn{2}{|c|}{ Treatment } & \multirow{2}{*}{$\begin{array}{c}\text { Visit } \mathbf{1} \text { (Day } \mathbf{0}) \\
\begin{array}{c}\text { Maxemeter Melanin } \\
\text { Average }\end{array} \\
17\end{array}$} & \multirow{2}{*}{$\begin{array}{c}\text { Visit } 2 \text { (Day 54) } \\
\begin{array}{c}\text { Maxemeter Melanin } \\
\text { Average }\end{array} \\
17\end{array}$} & \multirow{2}{*}{$\begin{array}{c}\text { Visit } 3 \text { (Day } 84 \text { ) } \\
\text { Maxemeter Melanin } \\
\text { Average } \\
17\end{array}$} & \multirow{2}{*}{$\begin{array}{c}\text { (Visit 2 - Visit 1) } \\
\begin{array}{c}\text { Maxemeter Melanin } \\
\text { Average }\end{array} \\
17\end{array}$} & \multirow{2}{*}{$\begin{array}{c}\text { (Visit } \mathbf{3} \text { - Visit } \mathbf{1}) \\
\text { Maxemeter Melanin } \\
\text { Average } \\
17\end{array}$} & \multirow{2}{*}{$\begin{array}{c}\text { (Visit } 3 \text { - Visit 2) } \\
\begin{array}{c}\text { Maxemeter Melanin } \\
\text { Average }\end{array} \\
17\end{array}$} \\
\hline Placebo & $\mathrm{N}$ & & & & & & \\
\hline & Mean & 236.6 & 221.4 & 213.2 & -15.2 & -23.4 & -8.2 \\
\hline & Std. Deviation & 98.3 & 65.6 & 64.2 & 53.5 & 48.6 & 31.6 \\
\hline & Minimum & 140.5 & 170.5 & 131.5 & -136.7 & -159.8 & -101.2 \\
\hline & Maximum & 586.8 & 450.2 & 427 & 126.7 & 54.7 & 43.7 \\
\hline & Median & 227 & 199 & 196.8 & -11.3 & -9 & -4.7 \\
\hline & \multicolumn{4}{|c|}{$p$-value for testing the change from previous visit } & 0.118 & 0.076 & 0.309 \\
\hline \multirow[t]{7}{*}{ Active } & $\mathrm{N}$ & 19 & 19 & 19 & 19 & 19 & 19 \\
\hline & Mean & 263.5 & 224.6 & 215 & -38.9 & -48.4 & -9.6 \\
\hline & Std. Deviation & 108.6 & 79.6 & 77.9 & 44.5 & 42.2 & 26.6 \\
\hline & Minimum & 142.5 & 111.8 & 114.2 & -179 & -194.7 & -83.2 \\
\hline & Maximum & 552 & 390 & 385.8 & 9.3 & 0.8 & 32.8 \\
\hline & Median & 249.3 & 203 & 190 & -34.2 & -37.3 & -7.5 \\
\hline & \multicolumn{4}{|c|}{$p$-value for testing the change from previous visit } & 0.001 & $<0.001$ & 0.091 \\
\hline \multicolumn{5}{|c|}{ p-value for testing the difference in change between Active and Placebo } & 0.186 & 0.049 & 0.639 \\
\hline
\end{tabular}

Table 3: Comparison of Mexameter Melanin Score between Active and Placebo groups

6 males. 22 of them are randomized into the active treatment group and 22 in placebo group, with equal numbers of each gender in each treatment group. Their ethnic groups were Chinese $(n=31)$, Malay $(n=3)$, Indian $(n=4)$ and others $(n=6)$. The duration of disease ranged from 1- 51 months (mean \pm SD; $7.28 \pm 6.16$ months).

36 Patients completed all 3 visits, 3 defaulted after visit 2 ( 1 active, 2 placebo), 1 withdrew after visit 2 (active), and another 4 withdrew in visit 3 ( 3 active, 1 placebo). All 44 patients were included in the analysis.

There were no significant differences in the baseline characteristics between the two treatment groups, in terms of age, duration of disease, gender, hours spent outdoor, frequency of sunscreen used, skin lightening agents and light therapies used.

\section{Efficacy analysis}

Table 2 shows the comparison of the mMASI Score between the active and placebo-treated groups. The median score fell significantly in both groups. For the active arm, the median score fell by 2.1 $(p<0.001)$ while the Placebo group fell by $1.8(p<0.001)$. Figure 1 shows the decrease of skin pigmentation compared with baseline. There was a greater decrease seen in those who received the oral supplement $(-2.1$ vs -1.8$)$, however this was not statistically significant $(\mathrm{p}<0.379)$. There was a directionally significant change in total mMASI from visit 2 to visit 3 (median $=-0.6, p=0.083$ ) in the active treatment arm versus the placebo arm $(\mathrm{p}=0.365)$.

The comparison of the Mexameter Melanin Score between the active treatment arm and placebo-treated groups is displayed in Table 3. There was an improvement in the Mexameter ${ }^{\bullet}$ Melanin score for both groups but only with a marginal difference in the score decrease between the 2 groups $(\mathrm{p}=0.049)$, as shown in Table 3 .

The Mexameter ${ }^{\circledR}$ Erythema score showed significant improvements in both groups, from visit 3 compared to visit 1 (Table 4 ), with a greater improvement in the group on the oral supplement, compared to placebo (median difference $=-30, p=0.018$, vs median difference $=-20$, $\mathrm{p}=0.020$ ). There was a trend towards greater decrease (Table 4 ) in score in the active treatment arm which was statistically significant $(\mathrm{p}=0.044)$ at 56 days, as is consistent with the anti-inflammatory activity of the carotenoids. 
Citation: Teo WL, Gan E, Jinghan A, Chuah SY, Alain K, et al. (2015) Double Blind Placebo Controlled Trial to Evaluate of the Effectiveness of a Dietary SupplementRichinCarotenoidsasAdjuncttoTopicalLighteningCreamfortheTreatmentofMelasma:APilotStudy.PigmentaryDisorders2:164.doi: 10.4172/2376-0427.1000164

Page 5 of 6

\begin{tabular}{|c|c|c|c|c|c|c|c|}
\hline \multicolumn{2}{|c|}{ Treatment } & \multirow{2}{*}{$\begin{array}{c}\text { Visit } 1 \text { (Day } \\
\text { 0) Maxemeter } \\
\text { Erythema Average } \\
17\end{array}$} & \multirow{2}{*}{$\begin{array}{c}\text { Visit } 2 \text { (Day } \\
\text { 54) Maxemeter } \\
\text { Erythema Average } \\
17\end{array}$} & \multirow{2}{*}{$\begin{array}{c}\text { Visit } 3 \text { (Day } \\
\text { 84) Maxemeter } \\
\text { Erythema Average } \\
17\end{array}$} & \multirow{2}{*}{$\begin{array}{c}\text { Visit } 2 \text { - Visit } \\
\text { 1) Maxemeter } \\
\text { Erythema Average } \\
17\end{array}$} & \multirow{2}{*}{$\begin{array}{c}\text { (Visit } 3 \text { - Visit } \\
\text { 1) Maxemeter } \\
\text { Erythema Average } \\
17\end{array}$} & \multirow{2}{*}{$\begin{array}{c}\text { (Visit } 3 \text { - Visit } \\
\text { 2) Maxemeter } \\
\text { Erythema Average } \\
17\end{array}$} \\
\hline Active & $\mathrm{N}$ & & & & & & \\
\hline & Mean & 370.7 & 336.1 & 338.6 & -34.6 & -32.1 & 2.5 \\
\hline & Std. Deviation & 62 & 75.2 & 49.7 & 66.7 & 48 & 69.1 \\
\hline & Minimum & 278.8 & 156.7 & 267 & -221.2 & -124 & -128.2 \\
\hline & Maximum & 504.2 & 468.8 & 437.2 & 50.8 & 49.8 & 179.5 \\
\hline & Median & 366.8 & 335.7 & 336.2 & -29.5 & -29.8 & -1 \\
\hline & \multicolumn{4}{|c|}{$p$-value for testing the change from previous visit } & 0.044 & 0.018 & 0.523 \\
\hline \multirow[t]{7}{*}{ Placebo } & $\mathrm{N}$ & 19 & 19 & 19 & 19 & 19 & 19 \\
\hline & Mean & 337.1 & 329 & 318.2 & -8.1 & -18.9 & -10.8 \\
\hline & Std. Deviation & 65.4 & 58 & 65.8 & 29.6 & 29.9 & 23.5 \\
\hline & Minimum & 215.7 & 235.5 & 192.7 & -59.7 & -76.3 & -56.7 \\
\hline & Maximum & 468.2 & 432.8 & 437.3 & 40.2 & 22.2 & 19.5 \\
\hline & Median & 328.7 & 323.2 & 302 & -3.3 & -19.7 & -16.7 \\
\hline & \multicolumn{4}{|c|}{$\mathrm{p}$-value for testing the change from previous visit } & 0.327 & 0.02 & 0.049 \\
\hline \multicolumn{5}{|c|}{ p-value for testing the difference in change between Active and Placebo } & 0.219 & 0.415 & 0.51 \\
\hline
\end{tabular}

Table 4: Comparison of Mexameter Erythema Score between Active and Placebo groups

\section{Safety assessments}

Adverse reactions (ADR) such as stinging, burning or pruritus were rarely reported by patients or observed by investigators in both study arms.

All in all, 3 patients had side effects. Two from active arm (with one complaining of burning sensation/redness on face and one had facial itch) and one patient from the placebo group (who complained of overall skin tone darkening). The adverse effects of burning, redness and itch has been attributed to the effects of the topical lightening cream. All patients who reported adverse effect withdrew from the study. In addition to the 3 who withdrew from adverse effects, 2 others defaulted, but no reasons were given for defaults.

\section{Discussion}

Carotenoids are known photoprotectants and beta-carotene supplements have been used for protection against ultraviolet (UV) light-induced erythema despite the fact that they would color the skin in orange. In addition to $\beta$-carotene or lycopene, earlier carotenoids, are also found in various fruit and vegetables. They exhibit absorption at wavelengths of UVB and UVA range, respectively and protect against UV-light-induced photo-damage [21,22].

Research into nutritional approaches as a complement to external strategies in sun protection and skin cancer prevention has gained much attention recently, as it has increasingly been shown that nutrients can reduce photo-oxidative damage. Ultraviolet A radiation has photooxidative properties and targets skin and blood antioxidants while also damaging cell components such as DNA. The traditional Greekstyle Mediterranean diet has been linked to low rates of melanoma in the Mediterranean region despite intense ultraviolet radiation exposure. This is attributed to the high content of dietary antioxidants, phytochemicals, $n-3$ polyunsaturated fatty acids, $n-9$ monounsaturated fatty acids, whilst being low in pro-inflammatory $n-6$ polyunsaturated fatty acids [23].

The sun protection factor of dietary components such as $\beta$-carotene or lycopene is significantly lower than that achieved by topical sunscreens and require several weeks to attain protective effects in the skin. However, an optimal supply of antioxidant micronutrients ensures an increased basal dermal defense against UV irradiation and contributes towards long-term protection and overall maintenance of skin health and appearance [20]. Aust O, et al. investigated the photoprotective effects of synthetic lycopene in comparison with a tomato extract and reported that supplementation with tomato-based products increases carotenoid levels in human serum [21].

Light induces primary and secondary photooxidative processes andcauses skin photoaging by accelerating the generation of reactive oxygen species. The mechanism of protective activity of carotenoids lies in the scavenging of reactive oxygen species. Additionally molecules with suitable structures absorb UV light and prevent direct damage of cellular targets [24].

Intake of $\beta$ Carotene is helpful in slowing down ultraviolet a induced photoaging in human skin by acting as a $\mathrm{O}_{2}$ quencher. Dietary $\beta$ carotene was found to inhibit matrix metalloproteinase 9 activation in ultraviolet A irradiated hairless mice [25-27]. Additional properties of these carotenoids include inhibition of melanin synthesis, including those in dark acne scars, freckles, dark underarms and age spots [28].

In addition, carotenoids also possess anti-inflammatory properties in wound healing and UV damage. Carotenoids suppress the UVR- or IL-1-induced inflammatory response in dermal fibroblasts by blocking the UVR induction of the matrix-eroding enzyme, MMP-1, providing enhanced protection from inflammation and premature aging caused by sun exposure [25].

Several dietary carotenoids are found distributed throughout human tissues including the serum, plasma and skin. Crystal Tomato ${ }^{\circ}$ carotenoids, derived from a unique breed of non-genetically modified white tomatoes, have been shown previously to have the highest bioavailability in the skin compared to other carotenoids. Using the spectroscopy scattering method, Hata TR demonstrated that significantly lower carotenoid concentration in the skin correlated with the presence of skin cancer and precancerous lesions i.e. basal cell carcinomas, actinic keratosis compared with region-matched skin of healthy subjects [26]. In addition, the addition of amino acid L-Cysteine in the supplement increase efficacy by boosting the liver's production of Glutathione, an important anti-oxidant [29,30].

In this prospective, double blind placebo controlled trial involving 44 patients, the effectiveness of this carotenoid-rich dietary supplement is evaluated. The group on the active treatment arm was shown by both clinical and objective assessments to produce improvements in melasma pigmentation after 12 weeks of treatment. 
Citation: Teo WL, Gan E, Jinghan A, Chuah SY, Alain K, et al. (2015) Double Blind Placebo Controlled Trial to Evaluate of the Effectiveness of a Dietary SupplementRichinCarotenoidsasAdjuncttoTopicalLighteningCreamfortheTreatmentofMelasma:APilotStudy.PigmentaryDisorders2:164.doi: 10.4172/2376-0427.1000164

Page 6 of 6

While the median mMASI score from Visit 3 to Visit 1 fell significantly in both groups, there was a greater decrease seen in the score in those who received the active oral supplement vs. the placebo group although this was not statistically significant $(\mathrm{p}<0.379)$.

However, it is interesting to note that there was a significant change in total mMASI from visit 2 to visit 3 (median $=-0.6, \mathrm{p}=0.083$ ) in the active treatment arm versus the placebo arm $(\mathrm{p}=0.365)$. Taking into consideration that there were 17 participants left, this shows a strong directional efficacy for the active treatment group and this difference might be borne out further should the study be extended to more subjects and more than 84 days.

In addition, there was also a greater improvement in the Mexameter Erythema score in the group on the oral supplement, compared to placebo. Again, although this difference was not statistically significant $(\mathrm{p}=0.415)$ at visit 3 the difference occurred earlier and was significant at visit 2 vs. visit $1(\mathrm{p}=0.044)$.

Overall these findings indicate that there were statistically significant improvements in the mMASI score, Mexameter Melanin score and the Mexameter ${ }^{\circ}$ Erythema score across both study arms, with greater improvements in those who received the active treatment group when compared to the placebo arm.

In conclusion, this study shows that active supplement potentially has an adjunctive role in melasma treatment, although further largerscale and longer studies are required to prove its effectiveness over topicals alone.

\section{Acknowledgements}

The authors would like to acknowledge Ms.Virlynn Tan for her assistance in the statistical analysis.

\section{References}

1. Jimbow K, Minamitsuji $Y$ (2001) Topical therapies for melasma and disorders of hyperpigmentation. Dermatol Ther 14: 35-45

2. Balkrishnan R, McMichael AJ, Hu JY (2006) Correlates of health related quality of life in women with severe facial blemishes. Int J Dermatol 45: 111-115.

3. Balkrishnan R, Kelly AP, Torok H (2004) Improved quality of life with effective treatment of facial melasma: the pigment trial. J Drugs Dermatol 3: 377-381.

4. Gupta AK, Gover MD, Nouri K, Taylor S (2006) The treatment of melasma: a review of clinical trials. J Am Acad Dermatol 55: 1048-1069.

5. Sheth VM, Pandya AG (2011) Melasma: a comprehensive update: part II. J Am Acad Dermatol 65: 699-714

6. Picardo M, Carrera M (2007) New and experimental treatments of chloasma and other hypermelanoses. Dermatol Clin 25: 353-362.

7. Draelos ZD (2007) Skin lightening preparations and the hydroquinone controversy. Dermatol Ther 20: 308-313.

8. Kim YJ, Uyama H (2005) Tyrosinase inhibitors from natural and synthetic sources: structure, inhibition mechanism and perspective for the future. Cell Mol Life Sci 62: 1707-1723.

9. Gupta RR, Mahajan BB, Garg G (2001) Chemical peeling evaluation of glycolic acid in varying concentrations and time intervals. Cosmetology 67: 28-29.

10. Javaheri SM, Handa S, Kaur I, Kumar B (2001) Safety and efficacy of glycolic acid facial peel in Indian women with melasma. Int J Dermatol 40: 354-357.

11. Erbil H, Sezer E, Tastan B, Arca E, Kurumlu Z (2007) Efficacy and safety of serial glycolic acid peels and a topical regimen in the treatment of recalcitrant melasma. J Dermatol 34: 25-30

12. Hurley ME, Guevara IL, Gonzales RM, Pandya AG (2002) Efficacy of glycolic acid peels in the treatment of melasma. Arch Dermatol 138: 1578-1582.

13. Garg VK, Sarkar R, Agarwal R (2008) Comparative evaluation of beneficiary effects of priming agents ( $2 \%$ hydroquinone and $0.025 \%$ retinoic acid) in the treatment of melasma with glycolic acid peels. Dermatol Surg 34: 1032-1039.
14. Stahl W, Sies H (2012) Photoprotection by dietary carotenoids: concept, mechanisms, evidence and future development. Mol Nutr Food Res 56: 287-295.

15. Sies H, Stahl W (2004) Nutritional protection against skin damage from sunlight Annu Rev Nutr 24: 173-200.

16. Di Mascio P, Kaiser S, Sies H (1989) Lycopene as the most efficient biologica carotenoid singlet oxygen quencher. Arch. Biochem. Biophys 274: 532-538.

17. Cantrell A, McGarvey DJ, Truscott TG (2003) Singlet oxygen quenching by dietary carotenoids in a model membrane environment. Arch Biochem Biophys 412: 47-54.

18. Stacewicz-Sapuntzakis M, Bowen PE (2005) Role of lycopene and tomato products in prostate health. Biochim Biophys Acta 1740: 202-205.

19. Rizwan M, Rodriguez-Blanco I, Harbottle A, Birch-Machin MA, Watson $\mathrm{RE}$, et al. (2011) Tomato paste rich in lycopene protects against cutaneous photodamage in humans in vivo: a randomized controlled trial. $\mathrm{Br} \mathrm{J}$ Dermatol 164: 154-162.

20. Wilhelm Stahl, Helmut Sies (2012) b-Carotene and other carotenoids in protection from sunlight. Am J Clin Nutr 96: 1179-1184.

21. Aust O, Stahl W, Sies H, Tronnier H, Heinrich U (2005) Supplementation with tomato-based products increases lycopene, phytofluene, and phytoene levels in human serum and protects against UV-light-induced erythema. Int J Vitam Nutr Res 75: 54-60.

22. Pandya AG, Hynan LS, Bhore R, Riley FC, Guevara IL (2011) Reliability assessment and validation of the Melasma Area and Severity Index (MASI) and a new modified MASI scoring method. J Am Acad Dermatol 64: 78-83.

23. Shapira N (2010) Nutritional approach to sun protection: a suggested complement to external strategies. Nutr Rev 68: 75-86.

24. Minami Y, Yokoi S, Setoyama M (2007) Combination of TLC blotting and gas chromatography-mass spectrometry for analysis of peroxidized cholesterol. Lipids 42: 1055-1063.

25. Fuller B, Smith D, Howerton A, Kern D (2006) Anti-inflammatory effects of CoQ10 and colorless carotenoids. J Cosmet Dermatol 5: 30-38.

26. Hata TR (2000) Non-invasive raman spectroscopic detection of carotenoids in human skin. Journal of Investigative Dermatology 115: 441-448.

27. Terao J, Minami Y, Bando N (2011) Singlet molecular oxygen-quenching activity of carotenoids: relevance to protection of the skin from photoaging. $J$ Clin Biochem Nutr 48: 57-62.

28. vonOppen- Bezalel (2006) Round-up: Colourless carotenoids may protect skin against inflammation and UV radiation. Fragrance Journal 48-53.

29. Witschi A, Reddy S, Stofer B, Lauterburg BH (1992) The systemic availability of oral glutathione. Eur J Clin Pharmacol 43: 667-669.

30. Gross CL, Innace JK, Hovatter RC, Meier HL, Smith WJ (1993) Biochemical manipulation of intracellular glutathione levels influences cytotoxicity to isolated human lymphocytes by sulfur mustard. Cell Biol Toxicol 9: 259-267. 